UDC 316.354:351/354

LBC 60.56

\title{
UNIVERSAL TRANSFORMATIONS OF MANAGED STRATEGIES FOR TRANSITION TO THE STATUS OF A TRANSITIONAL UNIVERSITY ${ }^{1}$
}

\author{
Mikhail V. Boguslavsky \\ Institute of Education Development Strategy, Russian Academy of Education, Moscow, Russian Federation
}

Natalya S. Ladyzhets

Udmurt State University, Izhevsk, Russian Federation

Egor V. Neborskiy

Moscow State Pedagogical University, Moscow, Russian Federation

Olga V. Sannikova

Udmurt State University, Izhevsk, Russian Federation

\begin{abstract}
The world is changing rapidly. New realities become the subject of conceptualization, established theoretical concepts give way to new emerging constructs. In particular, the authors have previously refined the concepts of "transit university" and "transitive university". In the context of global, national and regional challenges for the transition of a regional transit university to the status of a transitive university, the a position of the university leadership on creating an innovative university ecosystem as a driver for the $\overrightarrow{{ }^{2}}$ development of the region becomes fundamentally significant. Accordingly, the purpose of the study was to clarify the resources and direction of changes in the internal university management of a regional university, necessary to ensure its transitivity. Universal transformations of managerial strategies for transition to the

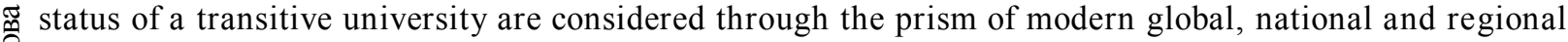
challenges. The article analyzes the need for diversification of educational national and regional systems against the background of universalization of requirements for higher education institutions of international rating agencies. In particular, attention is drawn to the fact that in the transition to the status of a transitive $\infty$ university, the diversification strategy also receives an internal component, represented by the need to find a Ii balance between traditional academic values and the values of market competition; between global and local awareness of opportunities for attracting students and teachers; between preferences in providing hard- and , soft skills. It also substantiates the importance of developing strategies for the constancy of tran sformation and the formation of a strong managerial core. The persistence of the interface between adaptive and proactive changes in the internal and foreign policies of the university administration is seen as an everyday strategic task that does not have unambiguous tactical decisions and is complicated by the existing gaps in the competencies of the heads of Russian and foreign universities. We consider the resources of transformational changes associated with the need for comprehensive digitalization of the university, with the development of a digital format of work in administration, the organization of educational and research processes as a new $\approx$ reality of university management, with the transition to working with big data; and also - formats for collegial $\infty$ interaction in creating innovative university ecosystems.
\end{abstract}

Key words: university management, transition strategies, transit university, transitive university, regional university, digital university, university innovation ecosystem. 


\title{
УНИВЕРСАЛЬНЫЕ ТРАНСФОРМАЦИИ УПРАВЛЕНЧЕСКИХ СТРАТЕГИЙ ПЕРЕХОДА К СТАТУСУ ТРАНЗИТИВНОГО УНИВЕРСИТЕТА ${ }^{1}$
}

\author{
Михаил Викторович Богуславский \\ Институт стратегии развития образования РАО, г. Москва, Российская Федерация \\ Наталья Сергеевна Ладыжец \\ Удмуртский государственный университет, г. Ижевск, Российская Федерация \\ Егор Валентинович Неборский \\ Московский педагогический государственный университет, г. Москва, Российская Федерация
}

\section{Ольга Владимировна Санникова}

Удмуртский государственный университет, г. Ижевск, Российская Федерация

\begin{abstract}
Аннотация. Мир стремительно меняется. Новые реалии становятся предметом концептуализации, устоявшиеся теоретические концепции уступают место новым формирующимся конструктам. В частности, авторами ранее уже было произведено уточнение понятий «транзитный университет» и «транзитивный университет». В условиях глобальных, национальных и региональных вызовов для осуществления перехода регионального транзитного вуза к статусу транзитивного университета принципиально значимой становится позиция руководства университета по созданию инновационной университетской экосистемы как драйвера развития региона. Соответственно, целью исследования было определено прояснение ресурсов и направленности изменений внутри университетского менеджмента регионального университета, необходимых для обеспечения его транзитивности. Универсальные трансформации управленческих стратегий для перехода к статусу транзитивного университета рассматриваются через призму современных глобальных, национальных и региональных вызовов. В статье анализируется необходимость диверсификации образовательных национальных и региональных систем на фоне универсализации требований к институтам высшего образования международных рейтинговых агентств. В частности, обращается внимание на то, что при переходе к статусу транзитивного университета стратегия диверсификации получает также и внугреннюю составляющую, представленную необходимостью нахождения баланса между традиционными академическими ценностями и ценностями рыночного конкурирования, между глобальной и локальной осведомленностью в возможностях привлечения студентов и преподавателей, между предпочтениями в обеспечении hard- и soft skills. Kpoме того, обосновывается значение развития стратегий постоянства преобразований и формирования сильного управленческого ядра. Постоянство сопряжения адаптивных и проактивных изменений внутренней и внешней политики университетской администрации рассматривается как повседневная стратегическая задача, не имеющая однозначных тактических решений и осложняемая существующими разрывами в компетенциях руководителей российских и зарубежных университетов. Рассматриваются ресурсы трансформационных изменений, связанных с необходимостью комплексной цифровизации вуза, с освоением цифрового формата работы в администрировании, организации образовательного и исследовательского процессов как новой реальности университетского управления, с переходом к работе с большими данными; а также форматы коллегиального взаимодействия при создании инновационных университетских экосистем.

Ключевые слова: университетское управление, стратегии перехода, университет-транзит, транзитивный университет, региональный университет, цифровой университет, университетская инновационная экосистема.
\end{abstract}

\section{Введение}

Социальные науки, работающие в актуализированном информационном поле, не могут абстрагироваться от тех вызовов, кото- рые лавинообразно нарастают, возникая из множества проблем глобального, национального и регионального уровней. Мир стремительно меняется. Развитие новых технологий расширяет диапазон инновационных возмож- 
ностей и увеличивает риски принятия односторонних и недостаточно обоснованных решений. В этом смысле сфера высшего образования получает эффект рискогенной мультипликации, когда, с одной стороны, многократно возрастают запросы внешних социальных контрагентов и возникает риск утраты систематизированной фундаментальной академической подготовки; а с другой - усиление конкуренции в мировом масштабе порождает проблемы необходимости соответствия референтным группам статусных университетов в ущерб вниманию к разрешению задач регионов и локальных сообществ. В связи с этим в западном академическом дискурсе была произведена актуализированная деконструкция понятия «интернационализация высшего образования» с предложением перехода к «глокализации» [Patel, Lynch 2013, 223-230; Patel 2017, 64-82], позволяющей осуществить деколонизацию генерации и распространения знания [De Wit et al. 2017, 1] c формированием равноправного партнерского диалога представителей глобальных и местных сообществ.

\section{Постановка проблемы}

Региональные российские университеты, по разным причинам не вошедшие в федеральные программы выделения приоритетных групп федеральных, научно-исследовательских и опорных вузов, получивших также возможность дополнительного финансирования, в результате оказываются еще менее конкурентными, рискующими увеличить уже существующий разрыв, вовлекая в этот процесс не только профессорско-преподавательский состав и студенчество, но и регион в целом. Утрата вектора инновационного развития вузов либо невнимание к нему в среднесрочной перспективе неизбежно приводит к снижению экономического потенциала региона.

В транзитивном обществе - обществе с инновационными ресурсами разрешения социально значимых проблем и перехода к новым качественным состояниям - для региональных университетов возникает драматическая дилемма: оставаться транзитным вузом - зоной транзита для последующей образовательно-трудовой миграции выпускников - либо вы- страивать стратегию транзитивного университета, в качестве базовой площадки формируя инновационную экосистему города или региона [Богуславский и др. 2018; Богуславский и др. web].

\section{Цель исследования}

Соответственно, целью исследования определено прояснение ресурсов и направленности изменений внутриуниверситетского менеджмента регионального университета, необходимых для обеспечения его транзитивности и адаптации к глобальным, национальным и региональным вызовам.

\section{Методология и методы исследования}

Выбранная тема исследования актуальна и многодисциплинарна. В этом случае обнаруживается встречное движение запросов, формируемых теорией и практикой. На рубеже XX-XXI столетий в развитии западной социальной теории в фокусе исследовательского интереса нередко оказывались переходные типы обществ. Это - «пространство потоков», или «пространство переливов», сетевого информационного общества, когда жесткие иерархические структуры испытывают воздействие горизонтально ориентированных сетевых структур, располагающих большими объемами актуальной информации и обеспечивающих оперативность в принятии конкурентных решений [Кастельс 2000]. Это - концепция «текучей современности», концепция переходного состояния общества, испытывающего инструментальный кризис несоизмеримости реальных инструментов эффективного действия и глобальной постановки задач [Бауман 2008; web]. Кроме того, сюда следует отнести парадигму новых мобильностей людей и вещей в глобальном масштабе [Урри 2012a; 2012б], приходящей на смену социологии социального. Они оказываются тесно связанными с теориями рефлексивного общества риска [Бек 2000] и эпохи радикализированной современности, когда процессы глобализации и самореализации получают не только рефлексивное измерение, но и становятся взаимообусловленными [Гидденс 2005]. Несколько ранее потребность в разработке теории переходных 
состояний социума в западной традиции была воспринята и проинтерпретирована представителями синергетического направления, предложившими теоретическую модель последовательных состояний социального порядка и причинно обусловленного хаоса как ресурса разрешения противоречий и перехода к новым формам социальной организации [Хакен 1980; Пригожин, Стенгерс 1986].

Тем не менее активное и многоуровневое содержательное акцентирование переходных состояний современного социума представлено различной, хотя и относительно однопорядковой терминологией. Собственно обращение к термину «транзитивный» фиксируется лишь с начала XX столетия при описании ритуала перехода одного из обрядовых комплексов в этнографическом исследовании А. ван Геннепа [Ван Геннеп 1999]. Применительно к социальным исследованиям оно лишь частично закрепилось при изучении миграционных процессов с позиций перехода от изучения дифференциации доходов к выявлению новых функциональных устремлений и возможностей при территориальных перемещениях [De Haas 2010]. Еще одна проекция применения прослеживается в организационном менеджменте, когда фактором, способствующим формированию новой идентичности при слиянии организационных структур, становится переходная идентичность [Clark et al. 2010].

Запросы практики обусловлены реальными проблемами регионов, например, испытывающих деструктивное воздействие пяти волн образовательно-трудовой исходящей миграции в направлении мегаполисов: абитуриентов, завершивших среднее образование; выпускников бакалавриата; выпускников магистратуры; профессионалов с небольшим стажем работы; и ближайших старших родственников, преимущественно еще трудоспособного возраста, переезжающих к детям. Регионы с университетами-транзитами при небольшой численности населения могут быть подвергнуты даже рискам утраты автономного административно-территориального статуса в случае, если не будут предприняты коллегиальные стратегические действия по переходу к транзитивной форме университета, формирующего экосистему инновационного взаимовыгодного партнерства всех ключевых акторов ре- гиона. В недавно завершенном эмпирическом исследовании Института образования Высшей школы экономики выделено пять типов российских регионов: регионы-магниты, регионы-транзиты, замкнутые регионы, регионыэкспортеры и пограничные регионы [Габдрахманов, Никифорова, Лешуков 2019]. Все они, за исключением регионов-магнитов, в той или иной степени испытывают деструктивное воздействие утраты наиболее конкурентоспособной и деятельностно активной молодежи, но в большинстве случаев эти процессы не получают комплексной экспертной аналитики и по существу рассматриваются как сугубо университетские.

Проведенные в 2018-2019 гг. качественные и количественные исследования со студентами Удмуртского государственного университета также свидетельствуют о том, что уже на старте подготовки преобладающее большинство бакалавров (как юношей, так и девушек) мотивировано на выезд из региона в течение ближайших 5-6 лет.

\section{Обсуждение и результаты}

Основным свойством транзитивного общества и транзитивного университета является постоянство освоения инновационных практик в достижении качественно новых состояний и результатов кооперативной деятельности для решения социально значимых задач, определяющих будущее. Здесь безусловной доминантой становится постоянство ускорения перехода к более технологичному и сложно структурированному будущему, обеспечивающему опережающее развитие. Характерно, что термин «развитие» приобретает интерпретативное значение драйвера инноваций.

В связи с этим можно сделать предположение о том, что терминологическое словосочетание «устойчивое развитие», впервые примененное на Всемирном экологическом форуме в 1972 г. [Meadows et al. web; Barbier 1987] и принятое в качестве основы для универсальной социоэкономической методологии на конференции ООН по окружающей среде и развитию в 1992 г. [Indicators of Sustainable Development... web], не вполне соответствует современным реалиям, нередко уже обозначаемым с позиций перехода не только к по- 
стиндустриальному обществу $3: 0$, но также и к обществу знаний 4:0. Несоответствие усматривается в том, что устойчивость не предполагает кризисных, порождающих многоуровневые риски состояний. Но ведь именно наличие кризисных состояний и необходимость комплексного разрешения проблем переносят смысловые акценты с «устойчивости» на постоянство «развития».

В связи с этим целесообразно сделать определенную корректировку негативистских оценок транзитивного общества, применительно к России понимаемому, например, как общество «со сложным процессом “накопления” социальных рискообразующих и конфликтогенных факторов, негативных социальных последствий управленческих решений, принимаемых в условиях неопределенности, вызванной финансово-экономическими кризисами» [Силласте 2016, 7]. Современный этап развития социума предъявляет такое радикальное ускорение изменений, что оно становится нормативным, а целеполагание на достижение устойчивости с исключением рисков и неопределенности может быть отнесено лишь к разряду идеально-типического и даже в этом случае - очевидно не актуального. Здесь, в терминологии социосинергетики, стратегической задачей экспертов и управленцев оказывается принятие решений, предупреждающих выход системы на точки бифуркации, «в силу невозможности предугадать ее самоорганизационный выбор в этот момент» [Мещерякова 2012,343].

Глобальные и национальные вызовы современным, все более взаимосвязанным обществам независимо от сферы социально-экономического, политического или социокультурного взаимодействия в итоге всегда оказываются спроецированными на сферу образования. «Глокальные» общества, удерживающие в фокусе стратегического анализа необходимость предъявлять повышенную конкурентоспособность на международном уровне и содействовать развитию местных экономик, территорий и сообществ, призваны думать о том, в каких направлениях должны изменяться их системы образования сегодня для обеспечения будущего.

Одним из основных современных вызовов становится диверсификация образова- тельных национальных и региональных систем на фоне универсализации требований к институтам высшего образования международных рейтинговых агентств. Особенностью диверсификации на современном этапе оказывается не только разнообразие образовательных учреждений, но и выраженный крен в сторону неолиберальных индивидуализированных ценностей и потребностей. Это означает постоянство расширения ресурсной базы инновационного обучения теории и практике, позволяющее снизить риски неопределенного будущего. В частности, для результативного управления актуальными и будущими изменениями необходим переход высшей школы к креативному, комбинаторному и проектному мышлению, поскольку «существующие знания и навыки имеют очень ограниченную ценность, если они не могут применяться новыми способами для получения новых знаний, которые решают сложные и масштабные проблемы для улучшения качества жизни всех людей» [Blessinger, Sengupta, Makhanya web].

Для обеспечения перехода регионального университета к статусу транзитивного руководству с необходимостью предстоит осуществить множество выборов, учитывая многоуровневые вызовы транзитивного общества - общества перехода к экономике знаний. Здесь стратегия диверсификации получает также и внутреннюю составляющую, представленную необходимостью нахождения баланса: между традиционными академическими ценностями университетской культуры и всевозрастающим давлением в направлении ценностей рыночного конкурирования; между глобальной и локальной осведомленностью в возможностях привлечения студентов и преподавателей [Marmolejo web]; между предпочтениями в обеспечении hard skills - профессиональных навыков работы с машинами и технологиями, которые можно измерить, и soft skills - навыков работы с бумагами и людьми, умственных и коммуникационных компетенций [Smirnov 2018]. Сюда же следует отнести поиски ресурсных возможностей открытия новых образовательных программ, поскольку постоянство инновационного обновления предложений образовательных продуктов оказывается не только условием расширен- 
ного привлечения студенческих контингентов, но и одним из ключевых факторов социального и экономического развития региона. Вероятно, можно сделать предположение о том, что ценность разнообразия многократно актуализируется, претендуя на полноправное включение в систему ценностей современной университетской культуры.

Еще один универсальный вызов, актуализируемый для всех уровней руководства в сфере образования в транзитивном обществе, может быть определен как развитие стратегий постоянства преобразований и формирование сильного управленческого ядра. Одно без другого принципиально не реализуемо. Недостаточность внимания к переменам получает множество аргументов - от необходимости соответствия жестким ведомственным требованиям и критериям оценки до предпочтений определенности и стабильности. Другая крайность заключается в недооценке рисков. В любом случае в современных условиях - это дрейфование либо к застою и статусному дауншифтингу в направлении вуза общей начальной подготовки, либо к принудительному объединению с более конкурентным университетом.

Будущее - за нормативностью стратегий постоянства изменений и результативных преобразований, обнаруживающих взаимную дополнительность институциональных и личностных интересов. Сегодня необходимо обращать внимание не только на содержательную сторону изменений, поскольку они подразумевают также административное подкрепление реорганизационными программами. И здесь важно не пропустить планирование и анализ содержательной и процессуальной сторон изменений. Если же этого не происходит и региональный университет оказывается не в состоянии сформировать сильное управленческое ядро, способное к постоянству инновационных изменений, он остается в статусе университета-транзита, создавая многоуровневые риски экономике, территориально-административной автономии и культуре региона.

Приведение компетенций руководителей университетов в соответствие с международными требованиями стало одной из задач правительства по разработке профессиональ- ных стандартов руководителей отечественной высшей школы. В современных условиях этот расширенный перечень компетенций определяется выполняемыми управленческими функциями, а также диапазоном взаимодействия с различными социальными контрагентами. Постоянство сопряжения адаптивных и проактивных изменений внутренней и внешней политики университетской администрации становится повседневной стратегической задачей, не имеющей однозначных тактических решений. Ее разрешение осложняется еще и существующими разрывами в компетенциях руководителей российских и зарубежных университетов, в частности, представленными: большим опытом работы западных руководителей в сфере организации международных научных исследований, коммерческих партнерских проектов, а также более широкими связями и коммуникациями на фоне меньшей длительности занятия ректорской позиции в университете [Жданов и др. 2019, 150].

Безусловным глобальным вызовом постоянству обновления управленческих стратегий университетов является цифровизация. Это новая образовательная реальность, одновременно формируемая будущим и формирующая это будущее. Скорость цифровой трансформации университета зависит от многих разнопорядковых факторов. Для рядового регионального университета, не располагающего возможностями дополнительного внешнего финансирования, принципиально значимыми становятся уровень видения стратегических горизонтов университетской администрацией, а также понимание ресурсов и процессов цифровой трансформации вуза, не ограничиваемой исключительно подготовкой специалистов для цифровой экономики. «Цифровой университет работает с цифровыми технологиями, “живет в цифре” и благодаря этому создает соответствующую среду, в которой будущие специалисты приобретают навыки работы с цифровыми технологиями» [Новая реальность образования... web]. Цифровизация вуза не только меняет характер подготовки студентов и охват студенческих контингентов, но и создает условия для приобретения навыков работы в команде, так же, как и проектного обучения. Результативным ресурсом этих 
трансформационных изменений являются: своевременность переподготовки, дополнительного обучения профессорско-преподавательского состава; разработка регламентов цифровизации образовательного пространства вуза; создание внешних университетских кафедр или практико-ориентированных центров компетенций на базе партнерских бизнесструктур, заинтересованных в подготовке высококлассных и многопрофильных IT-специалистов.

Освоение цифрового формата работы в администрировании, организации образовательного и исследовательского процессов это уже новая реальность университетского управления с освоением перехода к работе с большими данными. Цифровая трансформация изменяет структуру экономики, рынок труда, индивидуальные профессиональные траектории построения карьеры, создает цифровые кафедры, лаборатории и проектные офисы, требует новых нормативных актов, на законодательном уровне регулирующих многофункциональное взаимодействие в новой аналитико-технологической среде.

К такого же рода универсальным вызовам следует отнести формирование инновационных университетских экосистем, стремящихся стать инициативными драйверами инновационных экосистем регионов. Здесь ведущая роль остается за администрациями университетов, целенаправленно принимающими решения по определению формата продвижения к созданию инновационной экосистемы. Это может быть позиционирование и продвижение отдельных специализаций, в ближайшей перспективе способных повысить конкурентоспособность региона. В этом случае ключевыми становятся разработки конкретного исследователя или научной школы, привлекательные для партнерского взаимодействия в регионе и за его пределами, либо такого рода мобилизационным процессом оказывается концентрация интересов в направлении создания многопрофильного инновационного кластера.

В небольших регионах такие кластеры становятся более расположенными к прозрачному коллегиальному взаимодействию, к разработке и постоянству обновления общей стратегии. В более крупных регионах разработка общей стратегии может оказать- ся проблематичной, поскольку взаимодействующими акторами становятся спрофилированные сети, кластеры и мультифункциональные платформы развития, и в этом случае будет правильнее говорить о стратегической ориентированности как более мягкой и гибкой форме управления сотрудничеством с инициативными университетами. «Разработка стратегии университета может оказать существенное влияние на региональную политику, и наоборот. Тематические исследования показали, что университеты, которые сделали свое участие в инновациях основной частью своей миссии, проводят глубокие процессы трансформации, направленные на создание соединительной ткани между преподаванием в университете и исследованиями на всех уровнях. Везде, где инициируется такая стратегическая трансформация, она начинается на уровне руководства с тесной увязкой между университетскими и региональными стратегическими приоритетами» [Reichert web].

\section{Заключение}

Все эти универсальные трансформации университетских стратегий перехода к статусу транзитивного университета зависят от целого ряда многоуровневых факторов, испытывающих воздействие глобальных, национальных и региональных вызовов. На региональном уровне роль стратегического мышления руководителя вуза трудно переоценить. Актуализированное информационное поле, амбициозность в продвижении к будущим неочевидным прорывным результатам, способность создать управленческую команду единомышленников, инициативность и повышенная ответственность перед всеми партнерами по межинституциональному и межсубъектному университетскому взаимодействию мультиплицируют результативность универсальных трансформаций стратегий перехода к статусу транзитивного университета, закрепляя постоянство инновационных изменений в качестве нормативных и содействуя принятию комплексных управленческих решений по формированию взаимовыгодного сотрудничества в регионально-университетской экосистеме. 


\section{ПРИМЕЧАНИЕ}

${ }^{1}$ Исследование выполнено при финансовой поддержке РФФИ в рамках научного проекта № 18-013-00447-а «Транзитивный университет в условиях глобальных, национальных и региональных вызовов».

The study was carried out with the financial support of the RFBR of the scientific project no. 18013-00447-a "Transitive University in the face of global, national and regional challenges".

\section{СПИСОК ЛИТЕРАТУРЫ}

Бауман web - Бауман 3. Текучая модерность: взгляд из 2011 года: лекция Зигмунта Баумана [Электрон. публ.: Центр гуманит. технологий. 10.05.2011]// http://gtmarket.ru/laboratory/doc/ 4992.

Бауман 2008 - Бауман 3. Текучая современность. СПб.: Питер, 2008.

Бек 2000 - Бек У. Общество риска. На пути к другому модерну. М.: Прогресс-Традиция, 2000.

Богуславский и др. 2018 - Богуславский М.В., Ладыжеи Н.С., Неборский Е.В., Санникова О.В. Транзитный и транзитивный университеты в транзитивном обществе: уточнение и взаимосвязь понятий // Проблемы соврем. образования. 2018. № 5. С. 83-98.

Богуславский и др. web - Богуславский М.В., Ладыжеи Н.С., Неборский Е.В., Санникова О.В. Реализация социального заказа университетом в регионе: переход к транзитивности [Мир науки. 2018. T. 6, № 5]// https://mir-nauki.com/PDF/ 75PDMN518.pdf.

Ван Геннеп 1999 - Ван Геннеп А. Обряды перехода. Систематическое изучение обрядов. М.: Вост. лит. РАН, 1999.

Габдрахманов, Никифорова, Лешуков 2019 - Габдрахманов Н.К., Никифорова Н.Ю., Лешуков О.В. От Волги до Енисея... М.: НИУ ВШЭ, 2019.

Гидденс 2005 - Гидденс Э. Устроение общества: Очерк теории структурации. М.: Академ. проект, 2005.

Жданов и др. 2019 - Жданов П.А., Тростянская И.Б., Барсуков А.А., Полихина Н.А. Портрет современного ректора: необходимые компетенции на глобальном научно-образовательном рынке // Вопросы образования. 2019. № 2. C. 129-158.

Новая реальность образования... wеb - Новая реальность образования: что такое цифровой университет сегодня [РИА Новости. 22.07.2019] // https://na.ria.ru/20190722/
1556704299.html?fbclid=IwAR1Wd0Lvop10 YtEQkYGz8SDFS4qzz3W2sAIdxWk2xE72BwpTGXnOt5bg5U.

Кастельс 2000 - Кастельс М. Информационная эпоха: экономика, общество и культура. М.: ГУ ВШЭ, 2000

Мещерякова 2012 - Мещерякова Н.Н. Социологическая экспликация синергетических идей. Социология и общество: глобальные вызовы и региональное развитие: материалы IV Bcepoc. социол. конгресса (г. Уфа, 23-25 окт. 2012 г.). М.: POC, 2012. С. 336-344.

Пригожин, Стенгерс 1986 - Пригожин И., Стенгерс И. Порядок из хаоса: Новый диалог человека с природой. М.: Прогресс, 1986.

Силласте 2016 - Силласте Г.Г. Социальные риски кризисов транзитивного развития: методологический социологический дискурс // Гуманит. науки. Вестник Фин. ун-та. 2016. Т. 6, № 3 (23). С. 6-17.

Урри 2012a - Урри Дж. Мобильности. М.: Праксис, 2012.

Урри 2012б - Урри Дж. Социология за пределами обществ. Виды мобильности для XXI столетия. М.: ВШЭ, 2012.

Хакен 1980 - Хакен Г. Синергетика. М.: Мир, 1980.

Barbier 1987 - Barbier E. The Concept of Sustainable Economic Development // Environmental Conservation. 1987. № 14 (2). P. 101-110.

Blessinger, Enakshi, Makhanya web - Blessinger P., Enakshi S., Makhanya M. New Higher Education Literacies for a Sustainable Future [University World News. 20 October 2019. Iss. 571] // https://www.universityworldnews.com/ post.php?story=20191017120317521.

Clark et al. 2010 - Clark S.M., Gioia D.A., Ketchen D.J., Thomas J.B. Transitional Identity as a Facilitator of Organizational Identity Change During a Merger // Administrative Science Quarterly. 2010. Vol. 55, iss. 3. P. 397-438.

De Haas 2010 - De Haas H. Migration and Development: A Theoretical Perspective // International Migration Review. 2010. Vol. 44, № 1. P. 227-264.

De Wit et al. 2017 -De Wit H., Gacel-Avila J., Jones E., Jooste N. Introduction // The Globalization of Internationalization Emerging Voices and Perspectives. N. Y.: Routledge, 2017.

Marmolejo web - Marmolejo F. The Role of the University in an Era of Global Disruption [University World News. 20 Oct. 2019. Iss. 571] // https://www.universityworldnews.com/ post.php?story=20191014105831386.

Meadows et al. web-Meadows D.H., Meadows D.L., Randers J., Behrens W.W. III. The Limits to Growth // http://donellameadows.org/wp- 
content/userfiles/Limits-to-Growth-digital-scanversion.pdf.

Patel 2017 - Patel F. Deconstructing Internationali zation: Advocating Glocalization in International Higher Education // Journal of International and Global Studies. 2017. Vol. 8, № 2. P. 64-82.

Patel, Lynch 2013 - Patel F., Lynch H. Glocalization as an Alternative to Internationalization in Higher Education: Embedding Positive 'Glocal' Learning Perspectives // International Journal of Teaching and Learning in Higher Education. 2013. Vol. 25 (2). P. 223-230.

Reichert web-Reichert $S$. The Role of Universities in Regional Innovation Ecosystems [EUA Study] // https://www.eua.eu/downloads/ publicationseua $\% 20$ innovation $\% 20$ ecosystem \%20report\%202019-3-12.pdf.

Smirnov 2018 - Smirnov $S$. Management Education Priorities: Today and Tomorrow// Fundamentalis Scientiam. 2018. Vol. 1, № 24. P. 28-31.

Indicators of Sustainable Development... web Indicators of Sustainable Development: Guidelines and Methodologies // https:// sustainabledevelopment.un.org/content/ documents/indisd-mg2001.pdf.

\section{REFERENCES}

Bauman Z. Flowing Modernity: A View from 2011. Lecture of Zygmunt Bauman. Jelektronnaja publikacija: Centr gumanitarnyh tehnologij. URL: http://gtmarket.ru/laboratory/doc/4992.

Bauman Z., 2008. Flowing Modernity. Saint Petersburg, Piter.

Beck W., 2000. Risk Society. On the Way to Another Art Nouveau. M.: Progress-Tradicija.

Boguslavsky M.V., Ladyzhets N.S., Neborskiy E.V., Sannikova O.V., 2018. Transit and Transitive Universities in a Transitive Society: Clarification and the Relationship of Concepts. Problems of Modern Education, no. 5, pp. 83-98.

Boguslavsky M.V., Ladyzhets N.S., Neborskiy E.V., Sannikova O.V. Realization of a Social Order by a University in a Region: Transition to Transitivity. World of Science, 2018, vol. 6, no. 5. URL: https://mir-nauki.com/PDF/75PDMN 518.pdf.

Van GennepA., 1999. Rites of Passage. A Systematic Study of Rites. Moscow, Vostochnaja literatura RAS.

Gabdrakhmanov N.K., Nikiforova N.Yu., Leshukov O.V., 2019. From the Volga to the Yenisei... Moscow, Vysshaja shkola jekonomiki.

Giddens E., 2005. Organization of Society: Essay on the Theory of Structure. Moscow, Akademicheskij proekt.
Zhdanov P.A., Trostyanskaya I.B., Barsukov A.A., Polikhina N.A., 2019. Portrait of a Modern Rector: Necessary Competencies in the Global Scientific and Educational Market. Voprosy obrazovanija, no. 2, pp. 129-158.

New Reality of Education: What is a Digital University Today. RIA Novosti. URL: https://na.ria.ru/ $20190722 / 1556704299$.html? fbclid= IwAR 1 W d0Lvop 10 YtEQk Y Gz 8SDFS4 qzz 3 W 2 s A Idx W k2 x E 72 Bw-p T GXn Ot5bg5U.

Castells M., 2000. The Information Age: Economics, Society and Culture. Moscow, Vysshaja shkola jekonomiki.

Meshcheryakova N.N., 2012. Sociological Explication of Synergetic Ideas. Sociology and society: global challenges and regional development: Materials IV VSK (Ufa, October 23-25, 2012). Moscow, ROS, pp. 336-344.

Prigozhin I., Stengers I., 1986. Order from Chaos: A New Dialogue of Man with Nature. Moscow, Progress.

Sillaste G.G., 2016. Social Risks of Transitive Development Crises: Methodological Sociological Discourse. Gumanitarnye nauki. Vestnik Finansovogo universiteta, vol. 6, no. 3 (23), pp. 6-17.

Urry J., 2012a. Mobility. Moscow, Praksis.

Urry J., 2012b. Sociology Beyond Societies. Types of Mobility for the $21^{\text {st }}$ Century. Moscow, Vysshaja shkola jekonomiki.

Haken G., 1980. Synergetics. Moscow, Mir.

Barbier E., 1987. The Concept of Sustainable Economic Development. Environmental Conservation, vol. 14 (2), pp. 101-110.

Blessinger P., Enakshi S., Makhanya M. New Higher Education Literacies for a Sustainable Future. University World News. 20 October 2019. Iss. 571. URL: https://www.universityworld news. compost.php?story=2019101712 0317521 .

Clark S.M., Gioia D.A., Ketchen D.J., Thomas J.B., 2010. Transitional Identity as a Facilitator of Organizational Identity Change During a Merger. Administrative Science Quarterly, vol. 55, iss. 3, pp. 397-438.

De Haas H., 2010. Migration and Development: A Theoretical Perspective. International Migration Review, vol. 44, no. 1, pp. 227-264.

De Wit H., Gacel-Avila J., Jones E., Jooste N., 2017. Introduction. The Globalization of Internationalization Emerging Voices and Perspectives. New York, Routledge.

MarmolejoF. The Role of the Universityin an Era of Global Disruption. University World News. 20 October 2019. Iss. 571. URL: https://www.univer 
sityworldnews.com/post.php?story $=201910$ 14105831386

Meadows D.H., Meadows D.L., Randers J., Behrens W.W. III. The Limits to Growth. URL: http://donellameadows.org/wp-content/userfiles/ Limits-to-Growth-digital-scan-version.pdf.

Patel F., 2017. Deconstructing Internationalization: Advocating Glocalization in International Higher Education. Journal of International and Global Studies, vol. 8, no. 2, pp. 64-82.

Patel F., Lynch H., 2013. Glocalization as an Alternative to Internationalization in Higher Education: Embedding Positive 'Glocal' Learning Perspectives. International Journal of Teaching and Learning in Higher Education, vol. 25 (2), pp. 223-230.

Reichert S. The Role of Universities in Regional Innovation Ecosystems. EUA study. URL: https:// www.eua.eu/downloads/publications/ eua $\% 20$ innovation $\% 20$ ecosystem $\% 20$ report \%202019-3-12.pdf.

Smirnov S., 2018. Management Education Priorities: Today and Tomorrow. Fundamentalis Scientiam, vol. 1, no. 24, pp. 28-31.

Indicators of Sustainable Development: Guidelines and Methodologies. URL: https://sustainable development.un.org/content/documents/ indisd-mg2001.pdf.

\section{Information About the Authors}

Mikhail V. Boguslavsky, Doctor of Sciences (Pedagogy), Professor, Corresponding Member of the Russian Academy of Education, Institute of Education Development Strategy of the Russian Academy of Education, Zhukovsky St., 16, 105062 Moscow, Russian Federation, hist2001@mail.ru, https://orcid.org/0000-0002-3035-0090

Natalya S. Ladyzhets, Doctor of Sciences (Philosophy), Professor, Head of the Department of Sociology, Udmurt State University, Universitetskaya St., 1, 426034 Izhevsk, Russian Federation, lns07@mail.ru, https://orcid.org/0000-0002-6575-8977

Egor V. Neborskiy, Doctor of Sciences (Pedagogy), Associate Professor, Moscow State Pedagogical University, Pirogovskaya M. St., 1, Bld. 1, 119991 Moscow, Russian Federation, neborskiy@list.ru, https://orcid.org/0000-0002-8995-9802

Olga V. Sannikova, Doctor of Sciences (Sociology), Associate Professor, Udmurt State University, Universitetskaya St., 1, 426034 Izhevsk, Russian Federation, alexbor@udm.ru, https://orcid.org/0000-0003-1439-1340

\section{Информация об авторах}

Михаил Викторович Богуславский, доктор педагогических наук, профессор, член-корреспондент Института стратегии развития образования, Российская академия образования, ул. Жуковского, 16, 105062 г. Москва, Российская Федерация, hist2001@mail.ru, https://orcid.org/0000-0002-3035-0090

Наталья Сергеевна Ладыжец, доктор философских наук, профессор, заведующая кафедрой социологии, Удмуртский государственный университет, ул. Университетская, 1, 426034 г. Ижевск, Российская Федерация, lns07@mail.ru, https://orcid.org/0000-0002-6575-8977

Егор Валентинович Неборский, доктор педагогических наук, доцент, Московский педагогический государственный университет, ул. Пироговская М., 1, стр. 1, 119991 г. Москва, Российская Федерация, neborskiy@list.ru, https://orcid.org/0000-0002-8995-9802

Ольга Владимировна Санникова, доктор социологических наук, доцент, Удмуртский государственный университет, ул. Университетская, 1, 426034 г. Ижевск, Российская Федерация, alexbor@udm.ru, https://orcid.org/0000-0003-1439-1340 